\title{
Nasal Applicator Device
}

National Cancer Institute

\section{Source}

National Cancer Institute. Nasal Applicator Device. NCI Thesaurus. Code C149675.

Aid used for the administration of a drug by nose. 